\title{
Sosyal Bilgiler Dersinde Yaratıcı Drama Yönteminin Öğrencilerin Eleştirel Düşünme ve Çevresel Duyarlıklarına Etkisi *
}

\section{Özlem KARABULUT** ve Ebru GENÇTÜRK GÜVEN***}

Öz: Nüfus artışı doğal kaynakların tüketimini artırırken çevresel sorunları da beraberinde getirmiştir. İnsanoğlunun sürdürülebilir bir yaşamı inşa etmesi için bu sorunların çözümüne yönelik gerekli bilgi ve becerilere sahip olması oldukça önemlidir. Bu bakımdan eleştirel düşünme ve çevresel sorunlara duyarlı olma her bireyin sahip olması gereken nitelikler arasında yer almaktadır. Sosyal Bilgiler Öğretim Programı ise bu yetkinlikleri önceleyen bir vizyona sahiptir. Programın en temel becerilerinden biri eleştirel düşünmedir. Eleştirel düşünme formal eğitim sonunda bireyin sahip olması hedeflenen becerilerin başında gelmektedir. Buradan hareketle bu araştırmada, yaratıcı drama yönteminin 6.sınıf sosyal bilgiler dersinde öğrencilerin eleştirel düşünme becerisine ve çevresel duyarlıklarına etkisini belirlemek amaçlanmıştır. Araştırmada belirlenen amaç doğrultusunda nicel yaklaşıma dayalı olarak eşitlenmemiş kontrol gruplu yarı-deneysel desen kullanılmıştır. Araştırmaya 2017-2018 eğitim-öğretim döneminde Trabzon ilinde bulunan bir okulda 6.sınıfa devam eden biri kontrol, diğeri deney grubu olan 56 öğrenci katılmıştır. Dersler, deney grubunda “çevre kirliliği” konusuna yönelik hazırlanan ve 15 ders saati uygulanan yaratıcı drama etkinlikleriyle, kontrol grubunda ise programa dayalı öğretim etkinlikleriyle yürütülmüştür. Araştırmanın verileri "Eleştirel Düşünme Eğilim Ölçeği”" ile "Çevresel Duyarlılık" ölçeği kullanılarak elde edilmiştir. Araştırma sonucunda yaratıcı drama yönteminin tercih edildiği sosyal bilgiler derslerinin, programa dayalı öğretim etkinliklerine kıyasla, öğrencilerin eleştirel düşünme becerilerine ve çevresel duyarlılıklarına anlamlı seviyede katkı sağladığı belirlenmiştir.

Anahtar Kelimeler: Sosyal Bilgiler, Çevresel Duyarlılık, Yaratıcı Drama, Eleştirel Düşünme Becerisi.

\footnotetext{
*Bu çalışma, Özlem KARABULUT’un Doç.Dr.Ebru GENÇTÜRK GÜVEN danışmanlığında yürüttüğü yüksek lisans tezinden yararlanılarak yapılmıştır.

**Sosyal Bilgiler Öğretmeni, E-mail: ozlemkarabulut_2009@hotmail.com , Orcid No: 0000-0002-7251-054X

*** Doç.Dr. Trabzon Üniversitesi, Fatih Eğitim Fakültesi, Sosyal Bilgiler Eğitimi ABD. E-mail: egencturk@trabzon.edu.tr ORCID:0000-0002-4606-6449
} 
The effect of the creative drama method in social studies courses, on critical thinking and environment-consciousness on part of the students

\begin{abstract}
The population growth led to an increase in the consumption of natural resources, as well as to a number of problems affecting the environment. Knowledge and skills required to solve these problems are imperative for humanity to be able to build a sustainable life. In this context, critical thought and environmental consciousness are considered must-have characteristics for any individual. The Social Studies Curriculum, in turn, is structured around a vision prioritizing these competences. Critical thinking is one of the basic skills the program tries to develop. This competence is among the crucial requirements the individual is expected to meet by the end of formal training. Against this background, the present study aims to assess the creative drama method's effect on the critical thinking skills and environmentconsciousness levels of the students taking the 6th grade social studies course. To achieve this purpose, the study is designed as a quantitative one, based on a semi-experimental pattern with a non-equalized control group. The study was carried out with the participation of 56 students (28 in the experiment group and 28 in the control group) enrolled in 6th grade at a primary school in Trabzon province of Turkey, during the academic year 2017-2018. For the experiment group, the 15 hours of the classes were carried out with creative drama activities designed with reference to the issue of "environmental pollution”, whereas the control group received conventional instruction activities stipulated in the curriculum. The data were gathered using the "Critical Thinking Disposition Scale" and the "Environment-Consciousness Scale". The study led to the conclusion that, compared to conventional instruction activities stipulated in the curriculum, the social studies courses where the creative drama method was employed contributed significantly more to the development of critical thinking skills and environmentconsciousness levels of the students.
\end{abstract}

Keywords: Social studies, Environmental consciousness, Creative drama, Critical thinking skill

\title{
Giriş
}

21.yy bilginin değerini artırırken, bireylerin önceki yıllardan farklı olarak çoklu becerilere sahip olmasını gerektiren yönüyle öne çıkmaktadır. $\mathrm{Bu}$ yüzyılda bireyler bilgi edinmenin yanında, edindikleri bilgi ve becerilere dayalı olarak karar verebilmekte, sorumluluk almakta, diğer insanlarla doğrudan iletişim kurup işbirlikçi ortamlar oluşturarak grupla 
çalışabilme becerileri de kazanmaktadırlar. Bireylerin bu sürece uyum sağlamalarını kolaylaştırmak için eğitim sistemlerinin de çağın ihtiyaçlarını karşılayacak içerikte olması beklenmektedir. $\mathrm{Bu}$ amaçla günümüz eğitim sistemi öğrencilerin bilgiyi sorgulamasını, bir olayı çok yönlü bakış açısıyla inceleyip karar vermesini, ortaya attığı varsayımlarında kanıtlar kullanmasını, bağımsız ve özgür düşünen kişiler olmasını hedeflemektedir (Milli Eğitim Bakanlığı (MEB), 2006). Bu hedeflere ulaşmanın ise istenilen özelliklere sahip vatandaşlar yetiştirmekle gerçekleşebileceği söylenebilir. Ülkemizde okutulmakta olan Sosyal Bilgiler dersinin en temel amaçlarından biri de, öğrencilerin var olan yetilerini keşfetmek, onların sosyalleşmesine katkı sağlayarak iyi birer yurttaş olmalarını sağlamaktır. Bu yönüyle sosyal bilgiler öğrencilere, kaynağını sosyal bilimlerden alan seçilmiş bilgiler sunarak, onların sahip olması gereken tutum, değer, yetenek ve becerilerin kazandırıldığı bir ders olarak öne çıkmaktadır (Erden, 1998). Bu yönüyle gerçek yaşam problemlerine duyarlı, çevresel ve toplumsal kaynaklı sorunlara yönelik çözüm önerileri geliştiren bireylerin topluma dahil olmasında sosyal bilgiler dersi başı çekmektedir. Bu nedenle sosyal bilim konuları müfredatların ayrılmaz bir parçasıdır. Çocuklar birer yetişkin olduklarında, yaşamla başarılı bir şekilde mücadele edebilmeleri için gerekli bilgi, beceri ve değerleri bu dersler vasıtasıyla kazanacaklardır (Kemeh, 2014).

Günümüzde bireylerin karşı karşıya kaldığı sorunlardan belki de en önemlisi doğal çevre kaynaklı olanlardır. Gezegenimiz gittikçe artan kuraklık, seller, küresel ısınma, su, toprak ve hava kirliliği gibi birçok çevresel problemle karşı karşıyadır. Küresel iklim değişikliği gibi çevresel problemlerin oluşmasında antropojen etkinin önemli rol oynadığı kabul edilmektedir. Araştırmalar çevresel duyarlılıkla çevre dostu davranışlar arasında bağlantı olduğunu ortaya koymaktadırlar(Balunde, Perlaviciute ve Steg, 2019). Çevresel duyarlılığın gelişmesinde çocukların çevre konusunda deneyimlerinin artırılmasının önemli olduğu ifade edilmektedir (Vaughan ve ark., 2003). Bu nedenle daha karmaşık bir hal alan küresel dünyada, çevre eğitimi oldukça önemli hale gelmiştir. Yaratıcı drama yöntemi de çocuklara yaparak, yaşayarak öğrenme deneyimi sunduğu için çocukların çevresel duyarlılıklarının artmasında tercih edilebilecek en etkili yollardan biridir. Bertiz (2010) yaptığı çalışmada yaratıcı drama yönteminin çevre duyarlılığı üzerinde etkili olduğunu ortaya koymuştur. Çevresel duyarlılığın, çevreye yönelik doğru karar vermenin de ön koşulu olduğu belirtilmektedir(Wihardjo ve ark., 2017). Çevrenin korunmasına yönelik duyarlı olmak, aynı zamanda çevresel sorumluluk ve aktif vatandaşlık davranışını destekleyicidir(Erdoğan, 2016). Yaklaşık son 20 yıldır pek çok ülkede olduğu gibi Türkiye’de de doğal çevreye yönelik farkındalığın arttığı görülmektedir. 
Artan bu ilgiye paralel olarak, çevre bilincini geliştirmek için öğretim programlarına çevreye yönelik kazanım, değer ve becerilerin de dahil edilmeye başlandığı görülmektedir(Musser ve Diamond, 1999; MEB, 2018). Ayrıca çevreye yönelik bireylerin duyarlılıklarının farklı olmasında okulun hayati bir rol oynadığı ve öğretmenlerin de yapmış oldukları sınıf içi etkinliklerinin bu duyarlılığın gelişmesinde önemli olduğu belirtilmektedir(Musser ve Diamond, 1999; Tillmann, Katharina El Matany ve Duttweiler, 2018). Bu nedenle öğretmenlerin, öğrencilere gerçek yaşam deneyimi sunan, problemlere eleştirel bir yaklaşımla eğilmelerine imkan tanıyan öğretim yöntemlerini kullanması, çevresel duyarlılığın gelişmesi için oldukça önemlidir.

Sosyal Bilgiler dersi ülkemizde olduğu gibi Amerika Birleşik devletlerinde de çoğu öğrencinin, tüm öğretim kademelerinde en az ilgi gösterdiği derslerden birisidir (Shaughnessy and Haladyna,1985’den Akt; Anderson, 2017). Russel ve Waters (2010) bu ilgisizliğin çağdaş sosyal bilgiler sınıflarında öğrencinin pasif olduğu, ezbere dayalı öğretim yöntemlerinin kullanılmasıyla ilgili olduğunu belirtmişlerdir(Akt: Anderson, 2017). Sosyal bilgiler konularının öğretiminde kullanılan yöntemsel problemler nedeniyle öğrencilerin sahip oldukları olumsuz algı değiştirilmedikçe, dersin amaçlarına ulaşmasını ve öğrencilerin öngörülen becerileri edinmesini beklemek yanılgı olacaktır(Kemeh, 2014). Bu nedenle, öğrencilerin derse aktif katılımını sağlayacak yöntem ve tekniklerin kullanılması oldukça önem arz etmektedir. Bu yöntemlerden birisi de sosyal bilgiler dersinin içeriğine uygunluğu, öğrenci merkezli olması, onların derse aktif katılımını sağlaması, eleştirel düşünme ve karar verme becerilerini desteklemesi vb gibi özellikleriyle öne çıkan yaratıcı dramadır(Akhan ve Demirezen, 2015). Lee (1967; Akt; O’Hara, 1984), dramanın eğitime hayati derecede katkısı olduğunun yaygın olarak kabul edilmeye başlandığını, bu katkının bireyin kendini keşfetmesine, bireysel ve duygusal gelişimine ve insan ilişkilerinin anlaşılmasına yönelik olduğunu ifade etmektedir. Dramanın sınıfta kullanımının, basit bir tarihsel olgudan en kapsamlı kavrama kadar her türlü materyalin canlandırılabildiği, çocuklara demokrasi ideallerini yada aktif vatandaşlık ilkeleri gibi somut olmayan kavramların öğretilmesinde de etkili bir yöntem olduğu belirtilmektedir. Aynı zamanda drama, çocuğun bilgi birikiminin gelişimini hızlandırarak, genel algılama kapasitesini de artıran bir eğitim aracı olarak da görülmektedir (Kamerman, 1941). Bunların yanısıra tarih bilgisinin edinilmesi ve empati yoluyla geçmişin yorumlanarak tarihsel düşünme becerilerinin geliştirilmesinde de etkili olduğu belirtilmektedir(Goalen, 1996). 
Yaratıcı drama kavramına yönelik olarak alanyazında farklı tanımlar yer almaktadır. Bu tanımlarda yer alan ifadeler dikkate alındığında yöntemin şu özellikleri ön plana çıkmaktadır; grup etkinliği olması, grubu oluşturan bireylerin yaşamsal deneyim ve tecrübelerinden yararlanılması, bir olay, nesne ya da kavrama yönelik önceki bilgiler temel alınarak yeniden düzenlenmesi ve oyunlaştırılması, bir metne bağlı kalmaksızın bir duygunun, bir düşüncenin çeşitli tekniklerden faydalanılarak canlandırılmasıdır (Adıgüzel, 2017; San, 2009; Üstündağ, 2005).

Sosyal bilgiler öğretim programı öğrencilere kazandırılması gereken birçok beceriyi barındırmaktadır. Bu becerilerden belki de en önemlisi ve diğer becerilerle de yakından ilişkisi olan eleştirel düşünmedir. Sosyal bilgiler öğretim programında (MEB, 2005) yer alan eleştirel düşünme becerileri; bir kanıtı kullanma, sebep-sonuç ilişkisi kurabilme, varsayım türetme, olaylara çok yönlü bakarak genelleme yapma, farklı bakış açılarından yararlanarak açıklama yapma, kararları ve sonuçları sorgulama, gruplama yapma, olaylar hakkında kıstas belirleme, karşılaştırma yapma, faydalı bilgiyi tespit etme, kalıplaşmış bilgileri fark etme ve çıkarımda bulunmadır. Yaratıcı drama çalışmasında da kişi, farkında olmadan öğrenme ortamına aktif katılır ve grupla yada bireysel olarak yaparak yaşayarak öğrenme deneyimi edinir. Öğrenci, kendi yaptığı ile öğrenirken hem eğlenir, hem de duyu organlarını harekete geçirerek unutulmayacak deneyimler kazanır. Birey, bu deneyimlerini kazanırken var olan bilgilerini eleştiri süzgecinden geçirir, yeni öğrendiği bilgiler arasında bağ kurmaya çalışır, böylece kişi eleştirel düşünme becerisi kazanmaya başlar. Eleştirel düşünmenin asıl hedefi kişilere sorgulama ve akıl yürütme becerisini kazandırabilmektir. Bu açıdan bakıldığında sosyal bilgiler öğretim programının, öğrencilere kazandırmak istediği eleştirel düşünme becerisiyle ile yaratıcı drama yönteminin; "yaratıcılığı ve akıl yürütme gücünü geliştirme, iletişim becerilerini geliştirme, eleştirel ve yansız düşünebilme, işbirliği kurabilme, sosyal katılım sağlama, dil gelişimi, sözel ve mekânsal ifade becerisini geliştirme" gibi bazı temel amaçlarıyla doğrudan ilişkili olduğu görülür (Adıgüzel, 2017).

Bütün bu açıklamalar ele alındığında yaratıcı drama, öğrencinin öğrenme sürecine aktif olarak katılımını sağlayan, yaşantılardan yola çıkarak kişiye çoklu öğrenme ortamı sunarak öğrenmeyi sadece okulla sınırlamayan, çeşitli iletişim kaynaklarını kullanarak öğrencinin akademik başarısını destekleyen bir yöntem özelliği taşımaktadır. Bu yönüyle bakıldığında yaratıcı drama yöntemi Sosyal Bilgiler dersinde öğrencinin akademik başarısının gelişimine olanak tanıyan ve aynı zamanda sunduğu öğrenme ortamı ile öğrencilerin beceri gelişimini 
destekleyen etkili bir yöntem olarak görülebilir. Alanyazında farklı kademelerde yapılan çalışmaların da bunu desteklediği belirlenmiştir. Özellikle 2000'li yılların başından itibaren, yöntemin etkililiğini ortaya koyan çalışmaların son yıllarda arttığı görülmektedir. Hayat Bilgisi ve Sosyal Bilgiler derslerine yönelik olarak yürütülen çalışmalarda, yaratıcı drama yönteminin akademik başarıyı etkileyerek öğrenme seviyesini artırdı̆̆ı, bazı sosyal becerilerin kazandırılmasında etkili olduğu, öğrencilerin demokratik ve derse yönelik tutumlarını, değer yönelimlerini olumlu etkilediği tespit edilmiştir (Akdeniz, 2019; Akhan, Mert ve Acar, 2020; Aksüt, 2016; Günaydın, 2008; Kaf,1999; Karataş, 2011; Koç, 2013; Kozaner, 2019; Nayci ve Adıgüzel, 2017; Özcan, 2004; Özyürek, 2020; Saraç 2015; Uygungül Y1lmaz ve Kaf, 2019; Y1lmaz ve Ceylan, 2020; Zayimoğlu, 2006; Zengin, 2014).

Sonuç olarak günümüzde artan çevresel sorunların (su, toprak, hava kirliliği vb), çevreye daha duyarlı olan bireylere olan gereksinimi de artırdığı söylenebilir. Çevreye duyarlı olmak; doğal güzellikleri koruma, çevre dostu ürünleri kullanma, çevresel kirliliği önleme gibi her bireyin hassasiyet göstermesi gereken davranışları kapsamaktadır. Öğrencilerin bu davranışları kazanması, onların eleştirel düşünme becerisine sahip olmasıyla mümkün olabilir. Çünkü eleştirel düşünebilen bireyler, yaşamda karşılaştıkları çevresel, toplumsal problemleri sorgulayıcı bakış açısıyla ele alırlar. Bu gerekçelerle bu çalışmada Sosyal Bilgiler derslerinde dramanın kullanımına yönelik olarak alanyazındaki diğer araştırmalardan farklı olarak, eleştirel düşünme becerisi ve çevresel duyarlılık birlikte ele alınmıştır. Çalışmanın bu yönüyle özgün olduğu söylenebilir. Bu araştırmada yaratıcı drama yönteminin 6.sınıf Sosyal Bilgiler dersinde öğrencilerin eleştirel düşünme becerisine ve çevresel duyarlılıklarına etkisini değerlendirmek amaçlanmıştır. Belirlenen amaca ulaşmak için aşağıdaki sorulara yanıt aranmıştır.

Öğrencilerin eleştirel düşünme becerileri açısından;

1. Deney grubu ön-son test ortalama puanları arasında anlamlı bir farklılık var mıdır?

2. Kontrol grubu ön-son test ortalama puanları arasında anlamlı bir farklılık var mıdır?

3. Deney ve kontrol grubu son test ortalama puanları arasında anlamlı bir farklılık var midir?

Öğrencilerin çevreye duyarlılıkları açısından;

1. Deney grubu ön ve son test ortalama puanları arasında anlamlı bir farklılık var mıdır? 
2. Kontrol grubu ön ve son test ortalama puanları arasında anlamlı bir farklılık var midir?

3. Deney ve kontrol grubu son test ortalama puanları arasında anlamlı bir farklılık var midir?

\section{Yöntem}

Bu çalışmada yaratıcı drama yönteminin öğrencilerin eleştirel düşünme becerisi ve çevresel duyarlıklarına etkisini belirlemek için ön test - son test eşitlenmemiş kontrol gruplu yarı-deneysel desen kullanılmıştır. Deneme modelleri, neden-sonuç ilişkilerini tespit etmek amacıyla, gözlenmek istenen verilerin meydana çıkarıldığı araştırma modelleridir (Karasar, 2020). Deneysel çalışmalarda uygulanan ön ve son ölçümlerden elde edilen puanlara göre yapılan uygulamanın deney grubu üzerindeki etkisi belirlenebilir (Büyüköztürk, 2013).

Tablo1. Araştırmanın Modeli

\begin{tabular}{llll}
\hline Gruplar & Ön Test & Uygulama & Son Test \\
\hline $\begin{array}{l}\text { Deney } \\
\text { Grubu }\end{array}$ & EDEÖ, ÇDÖ & $\begin{array}{l}\text { Yaratıcı Drama } \\
\text { yöntemi } \\
\text { uygulaması }\end{array}$ & EDEÖ, ÇDÖ \\
\hline $\begin{array}{l}\text { Kontrol } \\
\text { Grubu }\end{array}$ & EDEÖ, ÇDÖ & $\begin{array}{l}\text { Programa } \\
\text { dayalı öğretim } \\
\text { uygulamaları }\end{array}$ & EDEÖ, ÇDÖ \\
\hline
\end{tabular}

\section{Çalışma Grubu}

Çalışma 2017-2018 eğitim öğretim yılı Trabzon iline bağlı bir ilçe merkez ortaokulu 6. sınıf öğrencileriyle (6A-sınıfi-28 öğrenci ve 6B-sınıfi-28 öğrenci) yürütülmüştür. Araştırma için bu okulun seçilmesinde öğretmen ve okul yönetiminin olumlu yaklaşımı ile okulun drama için fiziki olanaklara sahip olmasıdır. Aynı zamanda 6.sınıfa devam eden öğrencilerin bir yıldan fazla drama eğitimi almış olmaları da etkili olmuştur.

\section{Veri Toplama Araçları}

Araştırmada veri elde etmek amacıyla “Eleştirel Düşünme Eğilim Ölçeği” ve “Çevresel Duyarlık" ölçeği kullanılmıştır. Ertaş (2012) tarafından Türkçe'ye uyarlanan Eleştirel düşünme eğilim ölçeği (5'li Likert), Florida Üniversitesi araştırmacıları tarafından geliştirilmiştir. Ölçek “Katılım(11 madde), Bilişsel Olgunluk (8 madde) ve Yenilikçilik(7 madde)” olmak üzere 3 alt boyuttan oluşmaktadır. Toplamda 25 maddeden oluşan ölçeğin (11. Madde hata varyansının yüksek olması nedeniyle çıkarılmıştır) orjinalinde iç tutarlılık katsayısı (alfa) 0,94 iken, pilot çalışma sonucunda bu değer, 0,91 olarak bulunmuştur (Ertaş Kılıç ve Şen, 2014). Araştırmada kullanılan bir diğer ölçek ise; Açar (2010) tarafından geliştirilen "Çevresel Duyarlılık" 
ölçeğidir. 31 maddeden oluşan ölçek, "her zaman, bazen, hiçbir zaman” olmak üzere 3'li likert tipi seklinde hazırlanmıştır. Ölçek geçerlilik güvenirlik çalışması için 4. ve 5. Sınıf öğrencilerine uygulanmıştır. Ölçekte bulunan her bir maddeye yönelik faktör yükleri 0.409 ile 0.775 arasındadır. Ölçeğn iç tutarlılık katsayısı (Cronbach Alpha) 0,8216 olarak hesaplanmıştır. Verilerin analizinde ilişkili ve ilişkisiz örneklemler için t-testi kullanılmıştır. Araştırmanın haftalık uygulanan etkinliklerine ait deneysel işlem basamakları Ek 1 de verilmiştir.

\section{Bulgular}

Bu çalışma da ortaokul 6. sınıf programında yer alan “Çevremizde Kirlilik” ünitesiyle ilgili hazırlanan drama etkinlikleri kullanılarak uygulanan öğretim yönteminin öğrencilerin eleştirel düşünme becerisine ve çevresel duyarlıklarına etkisi incelenmiştir. Çalışmadan elde edilen veriler ve araştırma soruları doğrultusunda bulgular aşağıda yer almaktadır.

\section{Deney ve Kontrol Gruplarının Eleştirel Düşünme Eğilim Ölçeğine(EDEÖ) Ait}

\section{Ön Test Sonuçlarına İlişkin Bulgular}

Çalışmaya başlanmadan önce ilk olarak deney ve kontrol gruplarında bulunan öğrencilerin ele alınacak konuyla alakalı ön bilgileri bakımından aralarında anlamlı bir fark olup olmadığını tespit etmek için yapılan ön test ortalamalarına ilişkin t-testi sonuçları Tablo 2 de yer almaktadir.

Tablo 2. Deney ve Kontrol Grupları EDEÖ Ön Test Ortalama Puanlarına İlişkin t-Testi Sonuçları

\begin{tabular}{|c|c|c|c|c|c|c|}
\hline & $\mathbf{N}$ & $\overline{\mathbf{x}}$ & S & df & $\mathbf{t}$ & $\mathbf{p}$ \\
\hline Deney & 28 & 3,78 & 62648 & \multirow{2}{*}{54} & \multirow{2}{*}{,455 } & \multirow{2}{*}{,455 } \\
\hline Kontrol & 28 & 3,85 & ,54684 & & & \\
\hline
\end{tabular}

$\mathrm{P}>0.05$

Tablo 2'ye göre; deney grubunda bulunan öğrencilerin eleştirel düşünme eğilim ölçeğinden aldıkları puanların aritmetik ortalaması $X=3,78$, kontrol grubundaki öğrencilerin $\mathrm{X}=3,85$ olarak tespit edilmiştir. Ön test sonuçlarına göre kontrol grubu ve deney grubu öğrencilerinin eleştirel düşünme eğilimleri bakımından aralarında anlamlı bir farklılık bulunmamaktadır.

Tablo 3. Deney-Kontrol Gruplarının EDEÖ Sontest Ortalama Puanlarına İlişkin t-Testi Sonuçları

\begin{tabular}{llllllll}
\hline EDEÖ & $\mathrm{N}$ & $\bar{x}$ & $\mathrm{~S}$ & df & t & p
\end{tabular}




\begin{tabular}{lllllll}
\hline Deney & 28 & 4,84 &, 09521 & \multirow{2}{*}{54} & 14,719 &, $000^{*}$
\end{tabular}

$* \bar{p}<0,05$ olduğundan fark anlamlıdır.

Tablo 3’e göre deney grubunda yer alan öğrencilerin eleştirel düşünme eğilim ölçeğinden elde edilen toplam puanları aritmetik ortalaması $X=4,84$, kontrol grubu öğrencilerinin ise $\mathrm{X}=3,95$ olarak tespit edilmiştir. Ortalamalar arasındaki fark deney grubu lehine anlamlı bulunmuştur. $\mathrm{Bu}$ durum yaratıcı drama uygulamasının eleştirel düşünme eğilimini kazandırmada, diğer yöntemlere göre daha etkili olduğunu ortaya koymaktadır.

Tablo 4. Deney Grubunun EDEÖ Ön-Son test Ortalama Puanlarına İlişkin bağımlı t-Testi Sonuçları

\begin{tabular}{|c|c|c|c|c|c|c|c|}
\hline EDEÖ & $\mathbf{N}$ & $\overline{\mathbf{X}}$ & $\mathbf{S}$ & Xs - Xö & df & $\mathbf{t}$ & $\mathbf{p}$ \\
\hline Ön Test & 28 & 3,78 & 62648, & \multirow{2}{*}{1.0600} & \multirow{2}{*}{27} & \multirow{2}{*}{$-9,621$} & \multirow{2}{*}{, $000 *$} \\
\hline Son Test & 28 & 4,84 & ,09521 & & & & \\
\hline
\end{tabular}

$* \overline{\mathrm{p}}<0,05$ olduğundan fark anlamlıdır.

Tablo 4'de verildiği üzere, deney grubundaki öğrencilerin drama uygulamasından önce eleştirel düşünme eğilimlerinin ortalaması $X=3,78$ iken, uygulama sonrasında bu değer $X=4,84$ olarak belirlenmiştir. Bu bulgu, drama uygulamasının öğrencilerin eleştirel düşünme eğilimlerini arttırmada anlamlı bir etkiye sahip olduğunu göstermektedir.

Tablo 5. Kontrol Grubunun EDEÖ Ön-Son Test Ortalama Puanlarına İlişkin t-Testi Sonuçları

\begin{tabular}{|c|c|c|c|c|c|c|c|}
\hline EDEÖ & $\mathbf{N}$ & $\overline{\mathbf{X}}$ & $\mathrm{S}$ & Xs - Xö & df & $\mathbf{t}$ & $\mathbf{p}$ \\
\hline Ön Test & 28 & 3,85 & ,54684 & \multirow{2}{*}{-10143} & \multirow{2}{*}{27} & \multirow{2}{*}{$-1,388$} & \multirow{2}{*}{, $005^{*}$} \\
\hline Son Test & 28 & 3,95 & ,30438 & & & & \\
\hline
\end{tabular}

$* \mathrm{p}<0,05$ olduğundan fark anlamlıdır.

Tablo 5’de verildiği üzere, etkinlik merkezli öğretim yöntemleri öncesinde kontrol grubu öğrencilerinin eleştirel düşünme aritmetik ortalamaları $X=3,85$ iken, uygulama sonrasında bu ortalaması X=3,95 olarak belirlenmiştir. Ortalamalar arsındaki bu fark kontrol grubunda bulunan öğrencilerin eleştirel düşünme eğilimlerinin sontest lehine anlamlı olduğunu ortaya koymaktadır. Bu sonuç kontrol grubuna uygulanan programa dayalı aktif öğrenme yöntemlerinin etkisiyle açıklanabilir. 
Tablo 6. Öğrencilerin Çevresel Duyarlılık Ölçeği (ÇDÖ) Ön-Test Ortalama Puanlarına Yönelik t-Testi Sonuçları

\begin{tabular}{lccccccc}
\hline & Grup & $\mathbf{N}$ & $\overline{\mathbf{x}}$ & $\mathbf{S}$ & $\mathbf{d f}$ & $\mathbf{t}$ & $\mathbf{p}$ \\
\hline $\begin{array}{l}\text { Çevresel } \\
\begin{array}{l}\text { Duyarlılık } \\
\text { Ölçeği }\end{array}\end{array}$ & Deney & 28 & 2,48 &, 24484 & & & \\
\cline { 2 - 6 } & Kontrol & 28 & 2,34 &, 36123 & 54 & 1,732 &, 057 \\
\hline
\end{tabular}

$\mathrm{P}>0.05$

Tablo 6’daki verilere göre deney grubu çevresel duyarlılık ölçeği ön test puanları aritmetik ortalaması 2,48, kontrol grubunun ise 2,34 olarak hesaplanmıştır. Bu sonuçlar, kontrol ve deney gruplarının çevresel duyarlılık ölçeği ön test ortalama puanları arasında anlamlı bir farklı1ık bulunmadığını göstermektedir.

Tablo 7. Deney Grubunun ÇDÖ Ön-Son Test Ortalama Puanlarına İlişkin t-Testi Sonuçları

\begin{tabular}{ccccccc}
\hline ÇDÖ & $\mathbf{N}$ & $\overline{\mathbf{x}}$ & $\mathbf{S}$ & $\mathbf{d f}$ & $\mathbf{t}$ & $\mathbf{p}$ \\
\hline Ön Test & 28 & 2,48 & 24484 & 27 & $-7,95$ &, $000^{*}$ \\
\hline Son Test & 28 & 2,84 &, 04357 & 27 & &
\end{tabular}

*p $<0,05$ olduğundan fark anlamlıdır.

Tablo 7 incelendiğinde, deney grubu öğrencilerinin, çevresel duyarlılık ön test puanları aritmetik ortalamaları 2,48 iken, son testte bu değer 2,84 olarak bulunmuştur. Bu sonuçlar, deney grubu öğrencilerinin çevresel duyarlılıklarında anlamlı bir artış olduğunu ve yaratıcı drama yönteminin öğrencilerin çevresel duyarlılığını olumlu yönde etkilediğini göstermektedir.

Tablo 8. Kontrol Grubunun ÇDÖ Ön-Son Test Ortalama Puanlarına Yönelik t-Testi Sonuçları

\begin{tabular}{rccccccc}
\hline \multicolumn{1}{c}{ ÇDÖ } & $\mathbf{N}$ & $\overline{\mathbf{X}}$ & $\mathbf{S}$ & $\mathbf{X s}-\mathbf{X o ̈}$ & $\mathbf{d f}$ & $\mathbf{t}$ & $\mathbf{p}$ \\
\hline Ön test & 28 & 2,34 &, 36123 & \multirow{2}{*}{0.06} & 27 & \multirow{2}{*}{,- 913} & \multirow{2}{*}{, $000^{*}$} \\
\cline { 1 - 4 } Son test & 28 & 2,39 &, 30123 & & & & \\
\hline
\end{tabular}

$* \mathrm{p}<0,05$ olduğundan fark anlamlıdır.

Tablo 8'de verildiği üzere, kontrol grubuna uygulanan programa dayalı öğretimin öncesinde öğrencilerin çevresel duyarlılık puanlarının aritmetik ortalaması 2,34, öğretim sonrasında ise bu değer 2,39 olarak hesaplanmıştır. Bu sonuçlar kontrol grubu öğrencilerinin çevresel duyarlılıklarında anlamlı bir fark olduğunu göstermektedir.

Tablo 9. Öğrencilerin ÇDÖ Son Test Ortalama Puanlarına İlişkin t-Testi Sonuçları

\begin{tabular}{llclllll}
\hline ÇDÖ & $\mathbf{N}$ & $\overline{\mathbf{X}}$ & $\mathbf{S}$ & $\mathbf{X s}-\mathbf{X \ddot { 0 }}$ & $\mathbf{d f}$ & $\mathbf{t}$ & $\mathbf{p}$ \\
\hline Deney & 28 & 2,84 &, 04357 & \multirow{2}{*}{0.4482} & 54 & 7,791 & \multirow{2}{*}{, $000^{*}$} \\
\hline Kontrol & 28 & 2,39 &, 30123 & & & &
\end{tabular}


Tablo 9'daki veriler incelendiğinde deney grubu öğrencilerinin çevresel duyarlılık ölçeği son test toplam puanları $\overline{\mathrm{X}}=2,84$, kontrol grubu öğrencilerinin bu değeri $\overline{\mathrm{X}}=2,39$ olarak bulunmuştur. Bu değerler iki grubun son test ortalamaları arasında deney grubu lehine anlamlı bir farklılık olduğunu göstermektedir. Bu bulgu çevresel duyarlılığın arttırılmasında drama yönteminin araştırmada kullanılan diğer yöntemlere göre daha etkili olduğunu ortaya koymaktadır.

\section{Sonuçlar ve Tartışma}

$\mathrm{Bu}$ araştırmada, öğrencilerin eleştirel düşünme eğilimleri ve çevresel duyarlılıkları üzerinde yaratıcı drama yönteminin etkisi incelenmiştir. Elde edilen veriler sonunda yaratıcı drama yönteminin uygulandığı deney grubu öğrencilerinin her iki ölçeğe ait (EDEÖ ve ÇDÖ) son test ortalama puanlarının kontrol grubu öğrencilerinin ortalama puanlarına göre daha yüksek ve aradaki farkın anlamlı olduğu tespit edilmiştir. Bu durum, öğrencilerin aktif olarak öğrenme sürecine katılmaları, oyun ve eğlence ihtiyaçlarını öğrenme sırasında gidermeleriyle açıklanabilir. Karabulut (2020)'un araştırmasında da tespit edildiği üzere öğrenciler drama yönteminin kullanıldığı derslerde eğlendiklerini, etkinliklere katıldıkları için öğrenmenin daha kalıcı olduğunu, sonraki dersleri heyecanla beklediklerini ifade etmişlerdir. Yaratıcı drama yöntemi, öğrencilerin gerek yakın çevrelerinde gerekse küresel boyutta meydana gelen olayları analiz etmelerinde destekleyicidir ve bu durumun onların eleştirel düşünmelerini geliştirdiği belirtilmektedir.

Akınoğlu (2001) ve Koç (2011) yaptıkları çalışmada öğrencilerin derse aktif katılımının, elde ettikleri bilgiler üzerinde düşünmeleri ve analizde bulunmalarının eleştirel düşünme becerilerini geliştirdiğini ortaya koymuşlardır. Bu duruma bağlı olarak yaratıcı drama yönteminin öğrencilerin eleştirel düşünme becerilerini geliştirdiği söylenebilir.

Eğitim ortamında drama yönteminin kullanılması öğrencilerin bağlam temelli düşünmesini destekleyerek bilginin kalıcılığını ve akademik başarıyı artırmaktadır. Türküresin (2020), sosyal bilgiler derslerinde akademik başarıyı artırmada dramanın etkisini ölçen makalelere yönelik yürüttüğü meta-analiz araştırmasında, dramanın akademik başarıyı artırmada oldukça etkili olduğunu belirlemiştir. Bu yönüyle yaratıcı drama etkili yöntemlerden biri olarak görülmekte ve bütün eğitim kademelerinde bu yönteme yer verilmesi gerektiği birçok araştırmacı tarafından belirtilmektedir (Aykaç ve Adıgüzel 2011; Debre, 2008; Göncüoğlu, 2010; Kaf, 1999; Okvuran,1993). Yaratıcı drama uygulamaları ile öğrenciler 
öğrenme ortamında aktif olurlar, sorgulama becerileri gelişir, inceleme ve karar verme sürecine aktif olarak katılma imkanı bulurlar. Böylece problem çözme aşamasında yaparak yaşayarak öğrenmeyi deneyimledikleri için eleştirel düşünme becerileri gelişmiş olabilir. Drama yönteminin öğrencilerde bu özellikleri geliştirdiği çeşitli çalışmalarla da ortaya konulmuştur (Kaf,1999; Yağmur, 2010). Ayrıca Morris ve Welch (2004), yaptıkları çalışma ile sosyal bilgiler dersinde yaratıcı drama yönteminin, soyut konuların öğrenilmesi ve somutlaştırma aşamasında düşünme becerilerini geliştirmede etkili olduğunu bulmuşlardır. Sosyal bilgiler dersi yapısı gereği soyut kavramların ve konuların fazla olduğu bir derstir. Bu ders öğrencilere vatandaşlık sorumluluklarını ve yerel, küresel, toplumsal sorunları deneyimleme firsatı sunar. Drama yoluyla farklı toplumsal ve çevresel sorunları canlandırmak, öğrencilere o sorunun boyutlarını anlamalarına imkan vererek, duyarlılık geliştirmelerine yardımcı olur (Ezer ve Ulukaya, 2017). Öğrenciler de bu yöntemle eski dünya tarihi ile ilgili soyut konuları okuyarak senaryolar üretir, canlandırma yapar ve olayları anlamaya çalışırlar. Hikâyeler ve soyut konular somutlaştırılarak gözler önüne serildikçe, öğrenciler eski zamanlarda ve mekanlarda yaşanılanları yaratıcı drama yöntemi ile sınıf ortamına taşımış olurlar. Öğrenciler drama yöntemi kullanılırken fiziksel olarak hareket ederler ve bu hareket onların soyut konuları öğrenmelerinde etkili olabilir (Pieczura, 2013). Bu çalışmada ayrıca yaratıcı drama yönteminin öğrencilerin çevresel duyarlılıklarını geliştirdiği belirlenmiştir. Çevre eğitiminde yaratıcı dramanın etkililiğini değerlendiren çalışmalar sınırlı da olsa, yöntemin çevre eğitimindeki etkililiğine yönelik yürütülen araştırmalar da bu bulguyu destekler niteliktedir. Wake ve Birdsall (2020), "Lookout" adını verdikleri araştırma projesinde drama temelli öğrenme etkinliklerinin, öğrencilerin yaşadıkları yakın çevredeki sorunlara karşı daha derin bir anlayış geliştirerek, yaşadıkları yere daha güçlü bir aidiyet duygusuyla bağlanmalarını sağladığını ortaya koymuşlardır. Bu bulgu bizim çalışmamızdan elde ettiğimiz verilerle de örtüşmektedir. Yine benzer konuda yapılan diğer araştırmalara bakıldığında, drama yönteminin öğrencilere çevre konusunda farkındalık kazandırmada, çevre hakkındaki bilgilerinin artmasında ve öğrencilerin çevreye yönelik olumlu tutum geliştirmelerinde kullanılabilecek etkili bir yöntem olduğu ortaya konulmuştur (Bailey, 1994; Bailey ve Watson, 1998; Bakkaloğlu ve Özdemir Şimşek, 2021; Curtis ve diğerleri, 2013; Levey, 2005; McNaughton, 2004; Zayimoglu, 2006).

\section{Öneriler}

$\mathrm{Bu}$ çalışmada yaratıcı drama yönteminin öğrencilerin eleştirel düşünme ve çevresel duyarlılıkları üzerinde etkili olduğu belirlenmiştir. Buradan hareketle yaratıcı drama 
yönteminin farklı öğrenme alanlarına ve kademelerine yönelik uygulanması önemli görülmektedir. Bunula birlikte sosyal bilgiler öğretim programında yer alan problem çözme, karar verme vb. diğer beceriler üzerinde nasıl etkide bulunduğuyla ilgili çalışmalar yürütülebilir. Yöntem uygulanırken, daha önceden drama eğitimi almayan öğrencilerle yürütülecek çalışmalarda öğrencilere bu konuda temel eğitim verilmesi sürecin daha sağlıklı işlemesi açısından gereklidir. Özellikle temel eğitim ve ortaokul düzeyinde yapılacak çalışmalarda öğrencilere verilen yönergelerin sade ve anlaşılır olmasına dikkat edilmelidir. Aksi takdirde öğrenciler sıkılabilir ve grup dinamiği olumsuz etkilenebilir. Bir diğer önemli konu ise drama planlarının süreleridir. Uygulama süreleri iyi belirlenmemişse uygulama esnasında öğretmen sıkıntıya düşebilir. Bu nedenle uygulamaların birbirini takip eden ders saatleri içinde yapılması önerilir.

\section{Makalenin Bilimdeki Konumu}

Türkçe ve Sosyal Bilimler Eğitimi Bölümü/Sosyal Bilgiler Eğitimi

\section{Makalenin Bilimdeki Özgünlüğ̈̈}

Eleştirel düşünme becerisi öğretim programlarında ortak bir beceri alanı olarak yer almaktadır. Bilginin katlanarak artması, bireylerin ihtiyacı olan doğru bilgiye ulaşmasını daha önemli hale getirmiştir. Bu da bilgi yığınları içerinde hangi bilginin bilimsel, amaca uygun olduğunun eleştirel bir gözle değerlendirilmesini gerekli kılmıştır. Bununla birlikte nüfusun artması, çevreye ve doğal kaynaklar üzerindeki baskıyı artırmış ve çevreye duyarlı vatandaşlar yetiştirmenin önemi anlaşılmıştır. Toplumsal, çevresel, siyasal ve ekonomik sorunlara eleştirel bir bakış açısıyla yaklaşan bireyler, aynı zamanda çözümünde bir parçası olarak varlıklarını sürdürürler. Günümüzde artan çevresel sorunlar, insanlığın ortak mirası olan hava, su, toprak gibi doğal kaynakları ve canlı yaşamını tehdit etmektedir. Bu nedenle problemlere sorgulayıcı bir bakış açısıyla yaklaşan çevreye duyarlı bireyler yetiştirmek eğitimin temel amaçları arasındadır. $\mathrm{Bu}$ amaca hizmet eden öncü derslerden biri de sosyal bilgilerdir. Alanyazında eleştirel düşünme becerisi, çevre eğitimi ve drama yönteminin etkililiğine yönelik yapılan pekçok çalışma olmasına rağmen, çevresel duyarlılık ve eleştirel düşünmeyi birlikte ele alan bir araştırmaya rastlanılmamıştır. Bu nedenle bu çalışmanın etkin vatandaşlık bağlamında özgün ve sonuçları itibariyle alana katkı sağlayan bir araştırma olduğu düşünülmektedir. 


\section{Kaynaklar}

Açar, S. (2010). İlköğretim sosyal bilgiler dersinde gözlem gezisi uygulamasının öğrencilerin eleştirel düşünme becerisine ve çevre duyarlılı̆̆ına etkisi (Yayımlanmamış yüksek lisans tezi). Çanakkale Onsekiz Mart Üniversitesi, Sosyal Bilimler Enstitüsü, Çanakkale.

Adıgüzel, Ö. (2017). Eğitimde yaratıcı drama (10. bs.). Ankara: Pegem Akademi Yayıncılık.

Akdeniz, C. (2019). Sosyal Bilgiler dersinde yaratıcı drama yönteminin hayal gücüne yönelik bir eylem araştırması (Yayımlanmamış yüksek lisans tezi). Bartın Üniversitesi, Eğitim Bilimleri Enstitüsü, Bartın.

Anderson, C. (2017). Teaching social studies through drama. Undergraduate Honors Capstone Projects 258. Utah State University. Erişim: https://digitalcommons.usu.edu/honors/258

Aykaç, M. ve Adıgüzel, Ö. (2010). Sosyal bilgiler dersinde yaratıcı dramanın yöntem olarak kullanılmasının öğrenci başarısına etkisi. Kastamonu Eğitim Dergisi, 19(1), 297-314.

Akhan, N. ve Demirezen, S. (2015). Araştırma inceleme yoluyla öğrenme/öğretme stratejileri C. Dönmez ve K. Yazıcı (Yay.haz.), Sosyal bilgiler ögretimi içinde (s.145-174). Ankara: Pegem Yayınc1lık.

Akhan, E., Mert, H. ve Acer, H. (2020). Yaratıcı drama yöntemi ile değerler eğitimine bir örnek: Türk tarihinden yükselen evrensel mesajlar. Yaratıcı Drama Dergisi, 15( Özel Sayı1), 124.

Akınoğlu, O. (2001). Elestirel düsünme becerilerini temel alan fen bilgisi ögretiminin ögrenme ürünlerine etkisi (Yayımlanmamış doktora tezi). Hacettepe Üniversitesi, Sosyal Bilimler Enstitüsü, Ankara.

Aksüt, S. (2016). 5. Sinıf sosyal bilgiler dersinde drama yönteminin öğrenci başarısına, tutumuna ve kalıcılı̆̆a etkisi (Yayımlanmamış yüksek lisans tezi). Fırat Üniversitesi, Eğitim Bilimleri Enstitüsü, Elazığ.

Bailey, S. (1994). The Ecogame. Risley, Warrington, Cheshire: BNFL Education Unit.

Bailey, S. and Watson, R. (1998). Establishing basic ecological understanding in younger pupils: a pilot evaluation of a strategy based on drama/ role play. International Journal of Science Education, 20, 139-152. 
Bakkaloğlu, N. ve Özdemir Şimşek, P. (2021). An evaluation of the creative drama method used in third and fourth grade classes on environmental topics by teaching method. Journal of Baltic Science Education, 20(4), 590-611. Erişim: https://www.proquest.com/docview/2563788380?pqorigsite=gscholar\&fromopenview=true

Balunde, A., Perlaviciute, G. and Steg, L. (2019). The relationship between people's environmental considerations and pro-environmental behavior in lithuania. Frontiers Psychology, 10:2319. doi: 10.3389/fpsyg.2019.02319

Bertiz, H. (2010). Dramanın çevre bilinci oluşturmadaki rolü ve etkililiği (Yayımlanmamış Doktora Tezi). Gazi Üniversitesi, Eğitim Bilimleri Enstitüsü, Ankara.

Büyüköztürk, Ş., Kılıç Çakmak, E., Akgün, Ö.E., Karadeniz, Ş. ve Demirel, F. (2014). Bilimsel araştırma yöntemleri (17. Baskı). Ankara: Pegem Yayınları.

Curtis, D. J., Howden, M., Curtis, F., McColm, I., Scrine, J., Blomfield, T., Reeve, I., and Ryan, T. (2013). Drama and environment: Joining forces to engage children and young people in environmental education. Australian Journal of Environmental Education, 29(2), 182-201. Erişim: https://www.jstor.org/stable/26422824

Debre, İ. (2008). İlköğretim sosyal bilgiler dersi cŏgrafya konularının öğretiminde ders anlatım stratejisi olarak dramatizasyonun kullanılmasının ögrencinin başarı düzeyine etkisi (Yayımlanmamış yüksek lisans tezi). Yeditepe Üniversitesi, Eğitim Bilimleri Enstitüsü, İstanbul.

Er Türküresin, H. (2020). The effect of using creative drama method on student achievement in the social studies course: A meta-analysis study. International Online Journal of Education and Teaching (IOJET), 7(4), 1881-1896. Erişim: http://iojet.org/index.php/IOJET/article/view/1056

Erden, M., (1998). Ĕgitimde program değerlendirme (3. Baskı). Ankara:Anı Yayınevi.

Ertaş, H. (2012). Okul dişı etkinliklerle desteklenen eleştirel düşünme öğretiminin, eleştirel düşünme eğilimine ve fizik dersine yönelik tutuma etkisi (Yayımlanmamış doktora tezi). Hacettepe Üniversitesi, Eğitim Bilimleri Enstitüsü, Ankara.

Ertaş Kılıç, H. ve Şen, A.İ. (2014). 2UF/EMI eleştirel düşünme eğilimi ölçeğini Türkçeye uyarlama çalışması. Ĕ̈itim ve Bilim, 39(176), 1-12. 
Erdoğan, M. (2016) . Çevre eğitiminin doğuşu ve gelişimine kaynaklık eden hareketler ve çalışmalar. Çevre ve Enerji içinde (s.21-37), Aysel Aydın Kocaeren (Editör). Ankara:Nobel.

Ezer, F. ve Ulukaya, Ü. (2017). Teaching social studies with creative drama method. W. Wu, E. Koçoğlu ve Ö. Akman (Editör), New approaches in social studies education (1) içinde (s.151-162). ISRES Publishing. Erişim: https://www.isres.org/teaching-socialstudies-with-creative-drama-method-47-s.html\#.yun1x44zyoh

Goalen, P.(1996). The development of children's historical thinking through drama: A report on a history through drama project funded by Homerton College, Cambridge, Teaching History, No. 83, 19-26. Erişim: http://www.jstor.org/stable/43258432 Göncüoğlu, Ö. G. (2010). 6. Sinıf sosyal bilgiler dersi demokrasinin serüveni ünitesinin ögretiminde drama ve işbirlikçi öğretim yöntemlerinin öğrenci tutum ve başarısına etkisi (Yayımlanmamış yüksek lisans tezi). Niğde Üniversitesi, Eğitim Bilimleri Enstitüsü, Niğde.

Günaydın, G. (2008). İlköğretim 6. sınıf sosyal bilgiler öğretiminde drama yönteminin erişi ve tutum üzerindeki etkisi (Yayımlanmamış yüksek lisans tezi). Dokuz Eylül Üniversitesi, Eğitim Bilimleri Enstitüsü, İzmir.

Kaf, Ö. (1999). Hayat bilgisi dersinde bazı sosyal becerilerin kazandırılmasında yaratıcı drama yönteminin etkisi (Yayımlanmamış yüksek lisans tezi). Çukurova Üniversitesi, Sosyal Bilimler Enstitüsü, Adana.

Kamerman, S. E. (1941). Drama as a teaching tool, The Elementary English Review, 18(8), 295299. Erişim: http://www.jstor.org/stable/41383343

Karabulut, Ö. (2020). Sosyal bilgiler dersinde yaratıcı drama yönteminin öğrencilerin eleştirel düşünme becerisine ve çevresel duyarlılığa etkisi (Yayımlanmamış yüksek lisans tezi). Trabzon Üniversitesi, Eğitim Bilimleri Enstitüsü, Trabzon.

Karasar, N. (2020). Bilimsel araştırma yöntemi: Kavramlar, ilkeler, teknikler (36.bs). Ankara: Nobel Akademi Yayıncılık.

Karataş, O. (2011). Illköğretim 1. Kademe sosyal bilgiler dersi doğal afet ĕgitiminde drama tekniğinin öğrencilerin başarılarına etkisi (Yayımlanmamış yüksek lisans tezi). Kafkas Üniversitesi, Sosyal Bilimler Enstitüsü, Kars.

Kartal, T. (2009). Illköğretim 6. sınıf sosyal bilgiler dersi ilk çă̆ tarihi konularının öğretiminde drama yönteminin öğrenci başarısına etkisi (Yayınlanmamış yüksek lisans tezi). Selçuk Üniversitesi, Sosyal Bilimler Enstitüsü, Konya. 
Kemeh, M. (2014). Using solo drama to make the teaching of social studies engaging for students. INTE, Procedia - Social and Behavioral Sciences, 174 (2015), 2245 - 2252.

Koç. C. (2011). Aktif öğrenmenin okuduğunu anlama ve eleştirel düşünme üzerindeki etkileri. CÜ Sosyal Bilimler Dergisi, 35(1), 28-37.

Koç, İ. (2013). Öğretmenlerin sosyal bilgiler dersinde drama yöntemini uygulama ve drama tekniklerine ilişskin yeterliliklerinin belirlenmesi (Yayımlanmamış yüksek lisans tezi). Ahi Evran Üniversitesi, Sosyal Bilimler Enstitüsü, Kırşehir.

Kozaner, Y. Ç. (2019). Sosyal bilgiler dersinde bir yöntem olarak yaratıcı dramanın kullanımına yönelik öğrenci görüşleri: Bir dünya savaşı atölyesi. E-Uluslararası Eğitim Araştırmaları Dergisi, 10(3), 1-14.

Levey, S. (2005). Drama in environmental education. Green Teacher, 77, (15).

McNoughton, M.J. (2004). Educational drama in the teching of education for sustainability. Environmental Education Research, 10(2), 139-155.

MEB, (2006). İlköğretim Sosyal Bilgiler (4-5. Sınıf) Dersi Öğretim Programı, 2005, Ankara.

MEB, (2005). İlköğretim sosyal bilgiler öğretim programı ve kılavuzu. Ankara: Devlet Kitapları Müdürlüğ̈̈.

Morris, R. V. ve Welch, M. (2004). Scripted drama assesment in a middle school social studies class. Canadian Social Studies, 38(2). Erişim: http://www. educ. ualberta. ca/css/

Musser, L.M. and Diamond, K.E. (1999). The children's attitudes toward the environment scale for preschool children, The Journal of Environmental Education, 30(2),23-30. DOI: 10.1080/00958969909601867

Nayci, Ö. ve Adıgüzel, Ö. (2017). Sosyal bilgiler dersinde Yaratıcı Drama’nın bir yöntem olarak kullanılmasının öğrenci başarısına etkisi. Eğitim ve Bilim, 42, 349-365.

O'Hara, M. (1984). Drama in education: A curriculum dilemma theory into practice. Teaching the Arts, 23(4), 314-320. Erişim: http://www.jstor.org/stable/1476387

Okvuran, A. (1993). Yaratıcı drama eğitiminin empatik beceri ve empatik eğilim düzeylerine Etkisi (Yayımlanmamış yüksek lisans tezi). Ankara Üniversitesi, Sosyal Bilimler Enstitüsü, Ankara.

Özcan, H. (2004). İlköğretim 5. sinıf sosyal bilgiler dersi coğrafya konularının öğretiminde drama yönteminin kullanılması (Kazan ilçesi örneği) (Yayımlanmamış yüksek lisans tezi). Gazi Üniversitesi, Eğitim Bilimleri Enstitüsü, Ankara.

Özyürek, A. (2020). Sosyal bilgiler öğretmen adaylarının, yaratıcı drama dersinin etkililiğine yönelik görüşlerinin değerlendirilmesi. Kapadokya Ĕ̆itim Dergisi, 1(1), 35-51. 
Pieczura, M. (2013). Decidedly dramatic! The power of creative drama in social studies. Social Studies and the Young Learner 25 (3), 9-12.

San, İ. (2009). Eğitimde yaratıcı drama. Ankara Üniversitesi Eğitim Bilimleri Fakültesi Dergisi, (23)2, 533-582.

Saraç, A. (2015). Sosyal bilgiler dersinde drama yöntemi kullanılmasının tutum, başarı ve kalıcılı̆̆a etkisi (Yayımlanmamış yüksek lisans tezi). Balıkesir Üniversitesi, Sosyal Bilimler Enstitüsü, Balıkesir.

Uygungül Yılmaz, Ö. ve Kaf, Ö. (2019). The effects of creative drama method on students' attitude towards social studies with respect to learning styles. Çukurova Üniversitesi Ĕ̈itim Fakültesi Dergisi, 48(2), 1340-1366.

Üstündağ, T. (2005). Yaratıcılığa yolculuk. Ankara: Pegem yayıncılık.

Vaughan, C., Gack, J., Solorazano, H., and Ray, R. (2003). The effect of environmental education on schoolchildren, their parents, and community members: A study of intergenerational and intercommunity learning. The Journal of Environmental Education, 34(3): 12-21.

Wake, S., and Birdsall, S. (2020). Lookout for learning: Exploring the links between drama and environmental education pedagogies. Australian Journal of Environmental Education, 36(3), 234-245. doi:10.1017/aee.2020.22

Wihardjo, S.D., Hartati, S., Nurani, Y., and Sujarwanta,A. (2017). The effects of green schooling knowledge level and intensity of parental guidance on the environmental awareness of the early age student. Educational Research and Reviews, 12(5), 251-257.

Yağmur, E. (2010). 7.sınıf fen ve teknoloji dersinin yaratıcı drama destekli işlenmesinin eleştirel düşünme becerisi ve başarı üzerine etkisi (Yayımlanmamış yüksek lisans tezi). Sakarya Üniversitesi, Sosyal Bilimler Enstitüsü, Sakarya.

Yılmaz, S. ve Ceylan,T. (2020). Sosyal bilgiler derslerinde drama yöntemiyle öğretimin sosyal beceri, empatik beceri ve akademik başarıya etkisi. Bayburt Ĕ̆itim Fakültesi Dergisi, 15 (30), 385-412.

Zayimoglu, F. (2006). İlköğretim 6. Sınıf sosyal bilgiler dersi “coğrafya ve dünyamız" ünitesinde yaratıcı drama yöntemi kullanımının öğrenci başarısı ve tutumlarına etkisi (Yayımlanmamış yüksek lisans tezi). Gazi Üniversitesi, Eğitim Bilimleri Enstitüsü, Ankara. 
Zengin, E. E. (2014). Yöntem olarak yaratıcı drama kullanımının ilkokul 4. Sınıf sosyal bilgiler ögretim programındaki değerlere etkisi (Yayımlanmamış yüksek lisans tezi). Niğde Üniversitesi, Eğitim Bilimleri Enstitüsü, Niğde.

\section{Ek 1. Deneysel İşlem Süreci}

Bu araştırmada Çevremiz ve Kirlilik ünitesi deney ve kontrol grubu için ortak ünite olarak kullanılmıştır. Deney grubu olan 6/A sınıfı öğrencileri ile belirlenen konular drama atölyesinde drama yöntemini uygulanarak, kontrol grubunda (6B sınıfi) ise aynı konu belirlenen sürede etkinlik temelli olarak araştırmacı tarafından yürütülmüştür. Deneysel işlem aşamaları tablo 2 de sunulmuştur.

Tablo 1. Uygulama Süreci

\begin{tabular}{|c|c|c|c|}
\hline Hafta & $\begin{array}{l}\text { Ders } \\
\text { saati }\end{array}$ & Deney grubu & Kontrol grubu \\
\hline $\begin{array}{l}1 . \quad \text { Hafta } \\
(23- \\
27.10 .2017)\end{array}$ & 2 & $\begin{array}{l}\text { - Veri toplama araçlarının } \\
\text { uygulanması }\end{array}$ & $\begin{array}{l}\text { - Veri toplama } \\
\text { araçlarının } \\
\text { uygulanması }\end{array}$ \\
\hline $\begin{array}{l}\text { 2.Hafta } \\
(30- \\
03.11 .2017)\end{array}$ & $2+1=3$ & $\begin{array}{l}\text { - Yaratıcı drama yöntemi ile } \\
\text { “Ülkemiz ve Dünya” ünitesinin } \\
\text { nasıl işleneceği hakkında } \\
\text { bilgilendirme. } \\
\text { - Yaratıcı drama yöntemi ile } \\
\text { hazırlanan Tanışma oyunları(topla } \\
\text { tanışma oyunu, pile isim söyleme } \\
\text { oyunu, müzikli balonlar oyunu, } \\
\text { ping pano oyunu)ile öğrenciler } \\
\text { hakkında bilgiler elde edilir ve } \\
\text { çevre konusuna giriş yapılır.( (ders } \\
\text { planları ekte sunulmuştur) }\end{array}$ & $\begin{array}{l}\text { - Programa dayalı } \\
\text { öğretim ile hazırlanan } \\
\text { tanışma etkinlikleri } \\
\text { (top elimde isim söyle } \\
\text { oyunu)uygulanarak } \\
\text { öğrenciler hakkında } \\
\text { bilgiler edinilir ve } \\
\text { Çevre konusuna giriş } \\
\text { yapılır. }\end{array}$ \\
\hline $\begin{array}{l}\text { 3.Hafta } \\
(06- \\
10.11 .2017)\end{array}$ & $2+1=3$ & $\begin{array}{l}\text { - } \text { Ülkemiz ve Dünya ünitesi } 4 . \\
\text { Kazanımının } \text { Yaratıcı drama } \\
\text { Yöntemi ile işlenmesine }\end{array}$ & $\begin{array}{l}\text { - Ülkemiz ve Dünya } \\
\text { ünitesi } \\
\text { Kazanımının }\end{array}$ \\
\hline
\end{tabular}




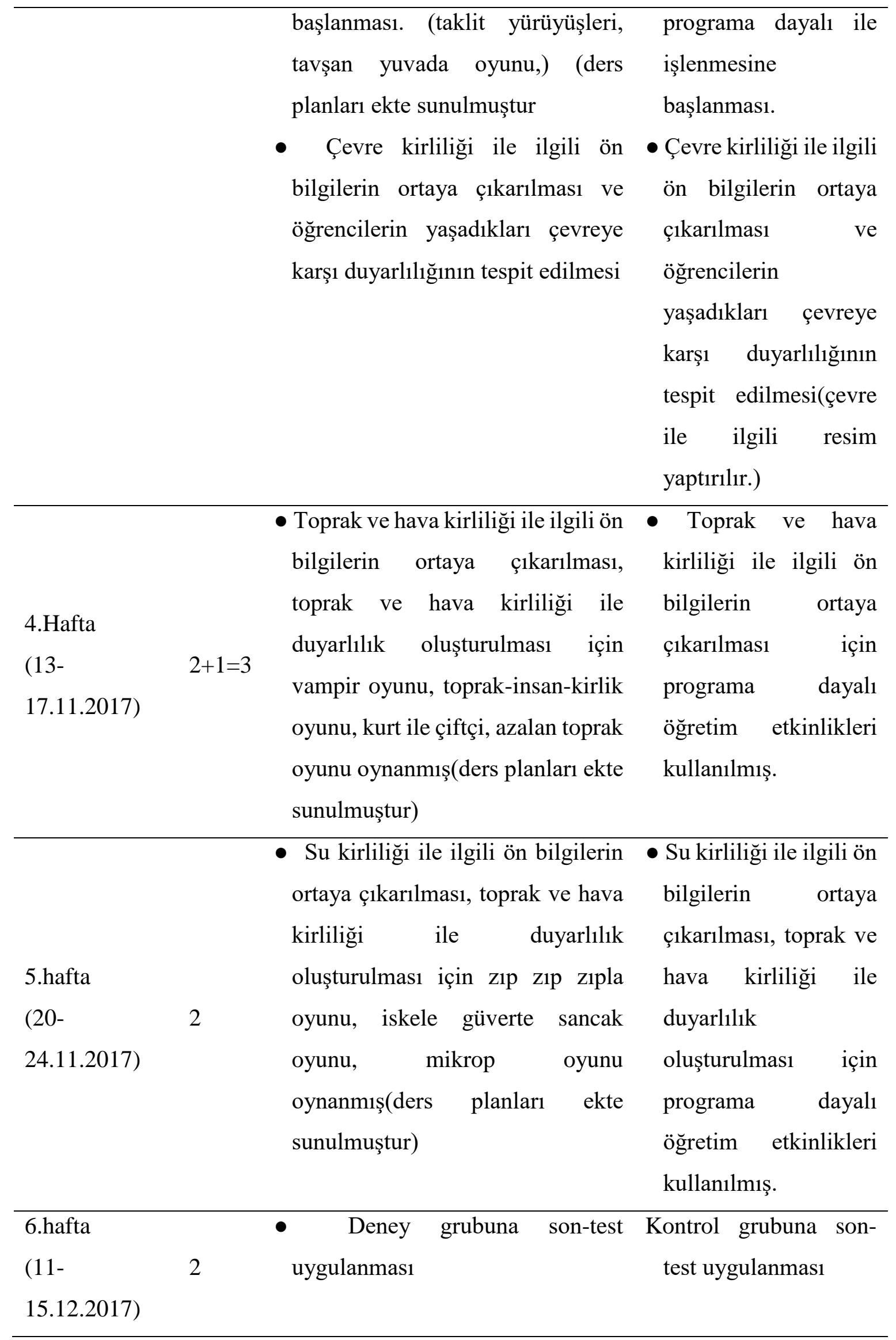


Şekil 2. Değerlendirme etkinliğine yönelik görüntü

Ek 3. Örnek etkinlik planı

KÜÇÜLEN GAZETE OYUNU: sınıf üyeleri 5 kişilik gruplara yarılır ve her gruba birer gazete kağıdı verilir. Müzik açılır ve grup üyeleri dans ederler müzik durduğunda grup üyeleri kendi gazete kâğıtlarının üstüne çıkmaya çalışır çıkamayan oyundan elenir ve tek kişi kalan kadar oyun devam eder

AMAÇ: Nüfusun artması, çevreyi işgal etmeleri ve işgal edilen yerde çevre kirliliğinin oluşması

\section{CANLANDIRMA}

A)Köy Ağası: Tarlasından fazla mahsul elde etmek için toprağa gübre veriyor ve köy halkını bu yönde eğitiyor

B)Ziraat mühendisi: Gübrelerin toprağa zarar verdiğini biliyor köy ağasını ve köylü halkı bu konuda uyarmaya çalışıyor

A) iș ADAMl: Tarım alanları para karşılığı alıyor ve yeşil alanlara hep fabrikalar kuruyor

B) Köylü: Tarım alanlarını satmamak yeşil alanları korumak istiyor

A) MUHTAR: Ev ve sanayi atıkları için belediye başkanından ayrı ayrı çöp konteyneri istiyor

B) BELEDIYE BAȘKANI: Ev ve sanayi atıkları için ayrı ayrı Çöp konteynırına gerek olmadığı bunun ekstra masraf olduğunu düşünüyor.

\section{DEĞERLENDIRME}

İstasyon tekniği uygulanarak bir grup: toprak kirliliği ile ilgili resim, başka bir grup: slogan diğer grubunda: şiir yazmaları istenir ve yapılan etkinlikler sınıf panosuna asılır.

4)SU KIRLILIĞi

$\begin{array}{ll}\text { DERS } & : \text { SOSYAL BILGILER } \\ \text { SINIF } & : 6 \\ \text { SÜRE } & : 2 \text { DERS SAATI(40+40) } \\ \text { OTURUM } & : \text { SU KIRLILIĞi } \\ \text { ARAÇ GEREÇ }:\end{array}$




\section{Statement of Problem}

Social Studies courses often draw the lowest levels of interest among the majority of the students, in Turkey as well as in the United States (Shaughnessy and Haladyna, 1985 quoted by Anderson, 2017). Russel and Waters (2010) refer to two issues as the root causes of such indifference: the rather passive position of the students, and the extensive use of memorizing in the instructional methods involved in contemporary social studies classes (quoted by Anderson, 2017). Unless the methodological approaches to the teaching of social studies topics can overcome the negative attitudes the students have, one cannot realistically expect the achievement of the course objectives and the development of the relevant skills on part of the students (Kemeh, 2014). Thus it is crucial to embrace methods and techniques to ensure active participation of the students. Thanks to its strengths in terms of ensuring the compatibility of the contents of the social studies course, providing a student-centric approach, facilitating active participation in the classes, and supporting critical thinking and decision making skills, creative drama stands out as one such method (Akhan and Demirezen, 2015). Lee (1967; quoted by O’Hara,1984) states that drama's essential contributions in education are now drawing widespread recognition, and that such contributions are mostly about helping the individual discover herself, understanding her individual and emotional development as well as human relationships. The use of drama in classroom settings is noted as an effective method for teaching intangible concepts such as the ideals of democracy or active principles of citizenship, as it allows conceptualizing and demonstrating any course material ranging from simple historical facts to most comprehensive concepts. Moreover, drama is considered as a means to expand the child's general perception capacity as it accelerates the process whereby the child obtains and accumulates knowledge (Kamerman, 1941). In addition, it plays a crucial role in the development of the skills of thinking about history through the accumulation of knowledge in the field and engaging in empathy (Goalen, 1996).

In this sense, the creative drama method helps the students to increase their academic achievement levels in social studies classes, and is effective in supporting the development of the students' skills and competences through the learning environment it enables. Recent environment problems human societies face (e.g. water, land, air pollution) underline the need for increased consciousness for the environment. Environment-consciousness, on the other hand, involves a number of behaviors requiring sensitive action and attitudes on part of the 
individual, such as protecting the nature, using environment-friendly products, and preventing pollution. The students can develop these behaviors by gaining and utilizing critical thinking skills and therefore adopt a questioning perspective towards the environmental and social problems they are to come across in life. That is why, in contrast to other studies in the literature regarding the use of creative drama in social studies courses, the present study focuses on the critical thinking skills and environment-consciousness in combination. In this sense, the study is unique and authentic, as it aims to assess the creative drama method's effect on the critical thinking skills and environment-consciousness levels of the students taking the 6th grade Social Studies course. In this context, the following research questions were investigated:

With reference to the critical thinking skills of the students;

1. Is there a significant difference between the mean pre-test and post-test scores of the experiment group?

2. Is there a significant difference between the mean pre-test and post-test scores of the control group?

3. Is there a significant difference between the pre-test and post-test scores of the experiment and control groups?

With reference to the students’ environment-consciousness levels;

4. Is there a significant difference between the pre-test and post-test results of the experiment group?

5. Is there a significant difference between the pre-test and post-test results of the control group?

6. Is there a significant difference between the pre-test and post-test results of the experiment and control groups?

\section{Material and Method}

The present study employed a semi-experimental pattern with pre-test and post-test, as well as a control group, to assess the creative drama method's effect on the students' creative thinking skills and environment-consciousness levels. The study was carried out during the school year 2017-2018 with 6th graders ( $\mathrm{n}=48$ students) at a secondary school in the district center of a district in Trabzon province. The Environment and Pollution unit was taught to the experiment group (class 6A) with the creative drama method at the drama theater, whereas the 
control group (class 6B) was taught the topic with conventional activities. The experiment lasted for 15 class hours (approximately 5 weeks). The "Critical Thinking Disposition Scale” and the "Environment-Consciousness Scale" was used to gather the data. The Critical Thinking Disposition Scale (5-point likert scale) adapted to Turkish language by Ertaş (2012) was originally developed by researchers at the University of Florida. The original version of the scale had an internal consistency factor (alpha) of 0.94, whereas the pilot study found the internal consistency factor to be 0.91 . The other scale used in the study was the "EnvironmentConsciousness Scale” developed by Açar (2010). The scale is comprised of 31 3-point likert items, with the answer options being "all the time, sometimes, and never". The internal consistency factor (Cronbach’s Alpha) of the scale was found to be 0.8216 .

\section{Findings}

According to the data collected in the study no significant difference existed between the mean scores the experiment and the control groups got in the "critical thinking disposition scale" and the "environment-consciousness scale" in the pre-test (see Table 3 and Table 7). The arithmetic mean of the students' post-test scores for the critical thinking disposition scale was 4.84 for the experiment group and 3.95 for the control group. The difference between the mean scores was found to be significantly in favor of the experiment group (see Table 4). The average score the students in the experiment group got with respect to their disposition towards critical thinking after the drama activities increased significantly (see Table 5). On the other hand, the average score the students in the control group got with respect to their disposition towards critical thinking after the classes based on conventional activities also saw a significant increase (see Table 6). No significant difference existed between the pre-test scores the control group and the experiment group got in the environment-consciousness scale (see Table 7). The arithmetic average of the scores the students in the experiment group got in the environmentconsciousness scale was 2.48 for the pre-test, and 2.84 for the post-test (see Table 8 ). This result indicates a significant increase in the environment-consciousness levels of the students in the experiment group, and suggests that the creative drama method had a positive effect on this front. On the other hand, the arithmetic average of the scores the students in the control group got in the environment-consciousness scale was 2.34 for the pre-test, and 2.39 for the post-test (see Table 9). These results indicate a significant difference in terms of the environmentconsciousness levels of the students in the control group. The finding is arguably due to the student-centric instruction activities carried out with the control group. The mean score the 
students in the experiment group got in the environment-consciousness scale was 2.84, which is significantly higher than the comparable figure for the students in the control group (2.39). The post-test scores show a significant difference in favor of the experiment group $(\mathrm{p}<.05)$. Based on this finding, one can forcefully argue that the drama method is more effective in increasing environment-consciousness levels, compared to other methods used in the context of the study.

\section{Discussion and Conclusion}

The study leads to the conclusion that the students in the experiment group subjected to the creative drama method saw a significant increase in their mean post-test scores in critical thinking disposition and environment-consciousness scales, compared to their scores in the pretest. The data also revealed that the mean scores the students in the experiment group got in the critical thinking disposition scale and the environment-consciousness scale were higher than the mean scores of their peers in the control group. These results may have been caused by a number of factors: shortcomings in terms of the control-group students' active involvement in the class, the fact that the control group was subjected to a one-way flow of information being provided by the teacher, and that the students did not need to make an effort to get the information, and thus, did not need to think about it or to make inferences about it.

Akınoğlu (2001) and Koç (2011) found that the students' active involvement in the class, spending time on and analyzing the knowledge they received led to improvements in critical thinking skills. This may be the fundamental reason why the creative drama method led to significant improvements in students' scores in critical thinking skills.

A number of studies so far noted that the drama method is one of the most effective methods in terms of achieving permanence in learning as it involves more implementation and active participation and less theoretical recitation, and proceeded to recommend that this method should be used more in all levels of education (Aykaç and Adıgüzel, 2011; Debre, 2008; Göncüoğlu, 2010; Kaf, 1999; Okvuran, 1993). Moreover, Morris and Welch (2004) found that the use of the creative drama method in social studies courses helped develop thinking skills in the abstraction stage, as well as the ability to learn abstract topics in general. Given the field it addresses, the social studies course is rich in abstract concepts. In the context of the drama method, the students read about the rather abstract flow of history, develop scenarios, perform and play them, and try to understand the developments. As the stories help provide a concrete 
picture pertaining to the otherwise abstract topics, the students can use the creative drama method to collectively think about and envisage the developments and incidents from previous ages and historical spaces. The present study also found that the creative drama method had a positive effect on the students' environment-consciousness levels. This finding is generally in tune with the results of other studies carried out so far on the use of the drama method in environment education. The existing studies in the literature also concur that the drama method can serve as an effective method to raise the students' awareness levels about environment issues (Bailey, 1994; Bailey and Watson, 1998; Bakkaloğlu and Özdemir Şimşek, 2021; Curtis et al., 2013; Levey, 2005, McNaughton, 2004; Zayimoglu, 2006). 